Sociedade, Contabilidade e Gestão, Rio de Janeiro, v. 10, n. 1, jan/abr 2015.

\title{
Relação entre o Disclosure da Sustentabilidade com a Governança Corporativa: Um Estudo nas Empresas Listadas no Ibrx-100
}

\section{Relationship between the Disclosure of Sustainability with the Corporate Governance: A Study in Companies Listed in Ibrx-100}

\author{
Emanoel Truta do Bomfim \\ Mestre em Ciências Contábeis - UnB/UFPB/UFRN \\ Jardim Cidade Universitária - João Pessoa/PB - 58051-900 \\ emanoeltruta@hotmail.com \\ Wellington dos Santos Teixeira \\ Mestre em Ciências Contábeis - UnB/UFPB/UFRN \\ Jardim Cidade Universitária - João Pessoa/PB - 58051-900 \\ welsantos79@gmail.com \\ Paulo Aguiar do Monte \\ Doutorado em Economia - PIMES/UFPE com Pós-Doutorado pela University of \\ Cambridge/UK \\ Professor Adjunto IV da Universidade Federal da Paraíba (UFPB) \\ Departamento de Economia - Universidade Federal da Paraíba. \\ Jardim Cidade Universitária, João Pessoa/PB - 58059-900 \\ pauloaguiardomonte@gmail.com
}

\begin{abstract}
Resumo
O objetivo deste estudo foi verificar a relação entre o disclosure da sustentabilidade com algumas características de governança corporativa nas empresas brasileiras de capital aberto. As características da governança corporativa estudadas foram a dualidade do CEO, nível de governança corporativa, comitê de sustentabilidade, diretores independentes, influência da comunidade, board interlocking e administração familiar. A análise teve como base 76 empresas listadas no IBRX-100 da BM\&FBovespa que foram acompanhadas no período de 2009 a 2011. A técnica de análise de conteúdo foi empregada nos relatórios corporativos, nas demonstrações financeiras e nos relatórios sociais ou de sustentabilidade das empresas investigadas com a finalidade de mensurar o nível de disclosure da sustentabilidade. O modelo de dados em painel com efeitos fixos e aleatórios foi utilizado para avaliar a relação entre o disclosure da sustentabilidade e das informações socioambientais com as características da governança corporativa das empresas investigadas. Os resultados encontrados demonstram que a administração familiar, a idade da companhia, a influência da comunidade, a presença de um comitê de sustentabilidade, o tamanho e o desempenho apresentam efeito positivo no disclosure da sustentabilidade. Por outro lado, a participação no Novo Mercado (NM) da BM\&FBovespa mostrou-se negativamente relacionada com o nível disclosure da sustentabilidade, demonstrando que a inserção neste nível diferenciado de governança corporativa não influencia na divulgação de informações pelas companhias investigadas.
\end{abstract}

Palavras-chave: Disclosure da sustentabilidade. Governança corporativa. IBRX-100. Empresas brasileiras. Dados em Painel.

Artigo publicado anteriormente nos Anais do $13^{\circ}$ Congresso USP de Controladoria e Contabilidade em 2013.

Artigo submetido em 14 de dezembro de 2014 e aceito em 23 de abril de 2015 pela Editora Fernanda Filgueiras Sauerbronn, após double blind review. 


\begin{abstract}
The aim of this study was to investigate the relationship between the disclosure of sustainability with some features of corporate governance in publicly traded Brazilian firms. The characteristics of corporate governance studied were duality of CEO, level corporate governance, sustainability committee, independent directors, influences of the community, board interlocking and family management. The analysis was based in a sample of the 76 companies listed in IBRX-100 BM\&FBovespa that were followed during the period 20092011. The technique of content analysis was used in corporate reports, financial statements and reports and social sustainability of the firms investigated in order to measure the level of disclosure of sustainability. The panel data model with fixed and random effects was used to assess the relationship between the disclosure of sustainability with the characteristics of the corporate governance of the companies investigated. The results show that the family administration, the age of the company, the influence of community, sustainability committee, the size and performance have positive effect on the disclosure of sustainability. However, participation in New Market (NM) corporate governance of BM\&FBovespa was negatively related to the level of sustainability disclosure, demonstrating that the insertion at this level differentiated corporate governance does not seem to influence the disclosure by enterprises investigated.
\end{abstract}

Keywords: Sustainability disclosure. Corporate gorvernance. IBRX-100. Brazilian firms. Panel Data.

\title{
1 Introdução
}

A história da humanidade é marcada por um processo constante e ininterrupto de transformações, que envolvem conceitos que se expandem por diversos campos, dentre os quais o econômico, social, ambiental e cultural. As empresas, na qualidade de agentes presentes no ambiente social, não poderiam ficar imunes a tais transformações. Nesse sentido, como reflexo de entendimentos a respeito de responsabilidade social, as empresas passaram a ter preocupações com práticas socioambientais visando legitimar suas ações perante os seus stakeholders.

Vale evidenciar que, internamente nas empresas, as transformações podem ocorrer tanto como uma resposta imposta por estímulos externos quanto como resultado de decisões de políticas internas, sendo que nos dois casos o foco é sempre algo presente no ambiente.

Para Hackston e Milne (1996), já não é mais aceito o fato de a única responsabilidade das empresas ser a maximização de lucros, haja vista que as atividades desenvolvidas por estas organizações causam impactos na economia, na sociedade e no meio ambiente, demandando dessas entidades ações que mimizem os problemas por elas causados, bem como a inclusão de políticas socioambientais nos objetivos organizacionais.

Nesse sentido, Weber e Marley (2012) destacam que nos últimos anos vem ocorrendo uma mudança no disclosure corporativo, que antes divulgava exclusivamente informações financeiras, passando a adotar uma nova e poderosa ferramenta para se comunicar com seus grupos de stakeholders: os relatórios de responsabilidade social corporativa ou relatórios de sustentabilidade corporativa. O relatório de sustentabilidade corporativa engloba informações econômico-financeiras, sociais e ambientais, ou seja, sobre os pilares da sustentabilidade (econômico, social e ambiental), destacando-se por evidenciar as políticas implantadas pelas 
empresas para minimizar os impactos ambientais decorrentes de suas operações, e as ações sociais desenvolvidas em prol da sociedade (WEBER; MARLEY, 2012).

De acordo com a Teoria dos Stakeholders, a implantação e divulgação das ações corporativas sustentáveis são uma parte do diálogo que as empresas devem manter com suas partes interessadas, pois demonstra o comportamento sócio-responsável dessas organizações, bem como legitima suas ações frentes ao seu público (GRAY; KOUHY; LAVERS, 1995; ADAMS; MCNICHOLAS, 2007).

Acerca desta temática, Gray et al. (2001) afirmam que as pesquisas anteriores têm investigado os possíveis determinantes do disclosure econômico-financeiro, social e ambiental por parte das empresas, enfocando particularmente nas características econômico-financeiras das companhias. Contudo, poucos estudos têm enfocado nos fatores do contexto interno as organizações que podem influenciar na divulgação dessas informações, principalmente no que tange aos aspectos da estrutura da governança (ADAMS, 2002; MICHELON; PARBONETTI, 2012).

Em outros termos, percebe-se uma ausência de preocupações dos pesquisadores a respeito de causas de foro interno e que provocam transformações nas empresas. Mesmo que não dito explicitamente, aceita-se como pressuposto válido a ideia que as transformações ocorrem sempre no sentido de fora para dentro, o que, evidentemente, constitui-se em um equívoco, isto pelo fato de as empresas serem agentes ativos.

Nesta perspectiva, considerando a necessidade de verificar a relação entre o disclosure da sustentabilidade praticado pelas companhias abertas brasileiras em relação a algumas características de governança corporativa (composição do conselho, estrutura, entre outras características), surge o seguinte problema de pesquisa: Qual a relação entre o disclosure da sustentabilidade (econômico, social e ambiental) praticado pelas empresas brasileiras e as características de governança corporativa?

Destarte, a realização desta pesquisa motiva-se pelo fato de que as políticas adotadas pela cúpula da governança corporativa das empresas ditam o comportamento que essas entidades devem tomar ao se relacionar com os seus stakeholders, bem como por que o processo de divulgação de informações corporativas passa necessariamente pela alta administração de qualquer organização, ou seja, são os gestores que definem as informações voluntárias que serão evidenciadas às partes interessadas (VERRECHIA, 2001). Além disso, este trabalho pode contribuir com a literatura existente na medida em que pode trazer novas evidências empíricas da relação entre o disclosure da sustentabilidade com os aspectos da governança corporativa, visto ser um tema ainda pouco explorado no cenário brasileiro.

Afora esta introdução, o trabalho contém mais quatro seções. A seção seguinte referese ao referencial teórico adotado, tendo como foco o disclosure de sustentabilidade e a governança corporativa embasados na Teoria do Stakeholders, Teoria da Legitimidade e Teoria da Divulgação. Em seguida, a seção 3 descreve a metodologia, abordando o modelo empírico e a base de dados utilizada no estudo. A seção 4 é destinada à análise e discussão dos resultados empíricos. Por fim, a última seção reporta-se às considerações finais.

\section{Referencial Teórico}

\subsection{Disclosure da Sustentabilidade}

A divulgação de informações socioambientais pelas empresas tem se tornado cada vez mais recorrente nas últimas décadas. Tal fato decorre, principalmente, da necessidade das empresas em atender aos stakeholders, que demandam, não somente informações financeiras, mas também sobre as ações e os projetos desenvolvidos pelas firmas em prol da sociedade, da 
preservação do meio-ambiente e dos impactos causados pelas atividades organizacionais no meio-ambiente e social.

A publicação de relatórios que contemplam essas informações deu-se no início da década de 1970. Inicialmente, a divulgação desses demonstrativos ocorreu de forma separada dos demais demonstrativos financeiros, e continha informações exclusivamente sobre o ambiente social e o relacionamento com os stakeholders (KOLK, 2004). Contudo, devido à pressão dos diversos grupos, como a sociedade, clientes, empregados, e outros stakeholders, hoje esses relatórios contemplam informações sobre o desempenho socioambiental, econômico e sobre as ações e projetos sociais e ambientais desenvolvidos pelas companhias, além do seu relacionamento com os interessados nas atividades corporativas.

Segundo Ballou, Heitger e Landes (2006), os relatórios de sustentabilidade corporativa divulgados atualmente pelas empresas contemplam a divulgação de informações financeiras e não financeiras sobre atividades operacionais, sociais e ambientais, demonstrando a capacidade das companhias em gerenciar os riscos relacionados ao negócio, evidenciando informações acerca dos pilares da sustentabilidade, ou seja, informações econômicas, sociais e ambientais.

Para Weber e Marley (2012), além de atender à necessidade dos diversos grupos interessados nas atividades desenvolvidas pelas companhias, esses relatórios tornaram-se uma importante ferramenta estratégica, onde as companhias buscam evidenciar o valor econômico e socioambiental criado pelas suas operações. Nesta perspectiva, Iatridis (2013) vê a divulgação de informações socioambientais pelas corporações como importante para os investidores, uma vez que eles usam-nas para avaliar o valor das empresas, fazer projeções futuras e avaliar as oportunidades e riscos do negócio. Para isso, os relatórios são estruturados de forma a evidenciar o valor econômico produzido e distribuído pela companhia aos seus acionistas e a sociedade, suas ações em prol da sociedade e do desenvolvimento sustentável, bem como sua relação com empregados, investidores e clientes (KOLK, 2004).

Assim, observa-se que os relatórios de sustentabilidade corporativa tornaram-se um veículo primordial para as companhias se comunicarem com toda a sociedade, bem como um meio necessário para legitimar suas ações, tanto que, nos últimos anos, esses demonstrativos passaram a ser vistos pelos dirigentes das empresas como peça imprescindível na estratégica organizacional.

\subsection{Governança Corporativa}

Qualquer política adotada em uma organização passa necessariamente pela sua alta gestão, sendo essa responsável pela implantação das normas e mecanismos que conduzem a relação com os investidores e os demais interessados nas atividades corporativas.

Esse conjunto de mecanismos é conhecido como governança corporativa. A governança corporativa, então, pode ser entendida como um conjunto de convenções culturais, instituições e regulamentos que regem a relação entre as administrações das empresas e os acionistas ou, até mesmo, entre outros grupos às quais as administrações, de acordo com o tipo de modelo, devem prestar contas (LEAL; CAMURI, 2008).

Nesta perspectiva, a governança corporativa é vista como um conjunto de práticas capazes de mitigar possíveis conflitos de interesse entre os provedores de capital e os agentes, fazendo com que os agentes (gestores) alinhem seus interesses com os dos acionistas na condução dos negócios corporativos. Segundo Silveira e Barros (2008), os mecanismos ou práticas adotadas pela governança corporativa podem ser internos e externos. Como exemplo de mecanismo de governança corporativa, tem-se o conselho de administração, a estrutura de propriedade e controle, a política de remuneração, a estrutura de capital, a competição no mercado de produtos, a competição no mercado de mão de obra dos gestores, o accountability, a separação entre os cargos de presidente do conselho de administração e presidente da diretoria executiva da empresa, a existência de um mercado de aquisições hostis e a publicação de Relação entre o Disclosure da Sustentabilidade com a Governança Corporativa: Um Estudo nas Empresas... 
informações regulares através dos relatórios e demonstrativos corporativos, dentre outros (SILVEIRA; BARROS, 2008).

Dentre os mecanismos da governança corporativa, o disclosure corporativo, que faz parte do accountability, é visto como uma dos meios disponíveis para diminuir possíveis assimetrias informacionais entre os gestores e os acionistas. Neste sentido, de acordo com Michelon e Parbonetti (2012), mecanismos de governança corporativa como as características do conselho de administração e a forma como ela é estruturada pode melhorar a qualidade das informações divulgadas pelas companhias, pois ajudam na transparência das ações praticadas pelos gestores.

A relação entre o disclosure corporativo e estrutura do conselho de administração e de outros aspectos da governança corporativa vêm sendo analisada nas últimas décadas com o intuito de verificar se esses mecanismos reduzem a assimetria e melhoram a qualidade das informações prestadas pelos gestores aos interessados nas companhias. Para Verrechia (2001), a análise dessa relação é importante uma vez que o processo de divulgação de informações corporativas passa necessariamente pelas políticas adotadas pelos gestores, sendo eles os agentes que escolhem as informações que serão disponibilizadas aos acionistas e demais interessados na companhia.

Desta forma, a divulgação de informações corporativas, sejam econômicas ou socioambientais, pode estar relacionada com as políticas e as práticas de governança corporativa adotada pelas companhias. A seguir, apresenta-se a relação existente entre características da governança corporativa e o disclosure de informações socioambientais pelas organizações.

\subsection{Governança Corporativa e Disclosure da Sustentabilidade}

A relação entre a governança corporativa e a divulgação de informações econômicas e socioambientais pelas companhias tem sido objeto de estudo e discussão nos últimos anos, demonstrando as associações existentes entre elas, bem como com outros determinantes.

Evidências sobre a relação entre o disclosure da sustentabilidade e a governança corporativa têm sido fornecidas pela Teoria dos Stakeholders e Teoria da Legitimidade, sugerindo que as companhias devem atender à necessidade informacional de todas as partes com que se relaciona, pois necessita legitimar suas ações perante o seu público (MICHELON; PARBONETTI, 2012). Para Jo e Harjoto (2012), a divulgação de informações socioambientais pelas empresas tem como objetivo a promoção da responsabilidade social corporativa, vista como uma extensão dos mecanismos de governança corporativa adotados pelas empresas para garantir a sustentabilidade de suas atividades, bem como o reconhecimento dos acionistas e dos demais stakeholders (ASHCROFTH, 2012).

Assim, as práticas de responsabilidade social e ambiental implementadas pelas companhias podem ser vistas como uma extensão da governança corporativa, que adota meios para demonstrar para o seu público-alvo que se preocupa com o desenvolvimento sustentável e o bem-estar da comunidade. Nesta direção, Aguilera et al. (2006) observaram que as diferenças existentes entre o volume de informações econômicas e socioambientais divulgadas pelas companhias sediadas nos Estados Unidos e no Reino Unido devem-se aos mecanismos de governança corporativa adotado em cada país, sendo que no Reino Unido há uma maior pressão da comunidade e dos investidores para que as empresas divulguem suas ações voltadas para responsabilidade social corporativa.

De acordo com Ho (2005), essas evidências sugerem que a pressão dos acionistas e de outros interessados, e a forma como a administração está estruturada podem influenciar no processo de divulgação de informações pelas companhias, bem como na responsabilidade 
social corporativa, visto que demandam das organizações mais accountability e transparência na divulgação de informações.

Hilmman, Cannela Jr. e Paetzold (2000) indicam que a participação de diretores independentes no conselho de administração das empresas também exerce um papel importante nesse processo, uma vez que essa prática cria um link entre a empresa e a comunidade, podendo aumentar a legitimidade das corporações. Nesta direção, Ionel-Alin, Emil e Maria (2012) encontraram indícios de que a participação de diretores independentes no conselho de administração pode ajudar a resolver os conflitos de agência existentes, bem como garantem transparência no que tange aos aspectos ambientais. Observa-se, portanto, que a presença de agentes não executivos nos conselhos administrativos das companhias parece influenciar no que tange as práticas socioambientais desenvolvidas pelas empresas, repercutindo, inclusive, na divulgação dessas informações para os investidores e para os demais interessados.

Segundo Michelon e Parbonetti (2012), tal fato se dá pela preocupação das companhias em legitimar suas práticas socioambientais para os seus stakeholders, bem como pela necessidade de se manter um canal aberto com a comunidade. De acordo com Iatridis (2013), a qualidade do disclosure ambiental praticado pelas empresas depende da eficácia dos mecanismos de governança corporativa, sendo que estes impactam diretamente na relevância das informações prestadas e melhoram a percepção dos investidores quanto à responsabilidade social corporativa (HO, 2005).

Silveira e Barros (2008), analisando os determinantes da qualidade da governança corporativa das companhias abertas brasileiras, encontraram evidências de que a estrutura de propriedade influencia na qualidade da governança das empresas brasileiras, sugerindo uma relação negativa entre o direito de controle do acionista e a qualidade da governa corporativa. Os resultados ainda demonstraram que as empresas maiores, emissoras de ADRs e com melhor desempenho apresentam, em média, melhor nível de governança, bem como que a adesão aos níveis diferenciados de governança corporativa da BM\&FBovespa parecem não influenciar o nível de governança das empresas.

Bergolöf e Pajuste (2005) em um estudo com empresas da Europa encontraram evidências de que o nível de disclosure varia de acordo com a empresa, havendo uma forte influencia do país de origem das companhias. Além disso, observaram que as informações são mais divulgadas por grandes empresas, por firmas com baixo endividamento, com alto índice de market-to-book e que apresentam uma estrutura de capital concentrada.

Por sua vez, Reverte (2009) encontrou evidências de que o disclosure da responsabilidade social corporativa pelas empresas espanholas é influenciado pela exposição na mídia, pelo o tamanho destas companhias e pelo tipo de atividade desenvolvido. Ainda, segundo o autor a Teoria da Legitimidade consegue explicar melhor a divulgação de informações socioambientais pelas firmas espanholas no período analisado.

Noutro estudo, Gamerschalag, Möller e Verbetten (2011) encontraram evidências de que a divulgação da responsabilidade social corporativa pelas empresas alemãs é consistente com a Teoria dos Custos Políticos. Os resultados demonstraram que o disclosure da responsabilidade social corporativa é influenciado pela visibilidade das empresas, estrutura acionária, relação com acionistas norte-americanos, bem como pelo tamanho e pelo setor econômico das firmas. Além disso, observou-se que a divulgação de informações ambientais é associada com a alta lucratividade das companhias.

Desta forma, nota-se que o disclosure da sustentabilidade parece ser influenciado pelas práticas de governança corporativa adotada pelas empresas, uma vez que estas buscam atender a pressão dos seus acionistas e demais interessados. Para tanto, utilizam mecanismos que garantam a legitimidade de suas ações, como a participação de diretores independentes no conselho de administração, criação de comitês ou diretorias incumbidas de desenvolver 
politicas socioambientais, bem como pela adoção de relatórios de sustentabilidade corporativa para divulgar para seus interessados que são sustentáveis e socialmente responsáveis.

\subsection{Teorias Relacionadas ao Disclosure da Sustentabilidade}

Algumas abordagens teóricas têm sido utilizadas para explicar o disclosure da sustentabilidade praticado pelas empresas, dentre as quais: a Teoria da Legitimidade, dos Stakeholders e a Teoria da Divulgação.

A Teoria da Legitimidade preceitua que, para continuar desenvolvendo suas atividades, as empresas devem agir de acordo com que a sociedade identifica como socialmente aceitável, dentro de um sistema social que envolve normas, valores, ideais e convicções (O’DONOVAN, 2002). Segundo Deegan (2002), esta relação pode ser vista dentro de uma perspectiva sistêmica, onde a companhia é influenciada pelo meio onde opera, bem como exerce influência sobre o ambiente externo o qual se relaciona. Nesta perspectiva, o disclosure corporativo é visto pela Teoria da Legitimidade como um importante instrumento pelo qual os gestores influenciam as expectativas externas sobre sua organização, assim como necessário para legitimar suas atividades perante suas partes relacionadas.

A Teoria dos Stakeholders exposta por Freeman (1984) defende que as empresas devem atender aos interesses de todas as partes com que se relaciona e não apenas aos interesses dos detentores do capital, destacando que um stakeholder é qualquer grupo ou indivíduo que pode afetar ou ser afetado pelos objetivos das organizações (ROBERTS, 1992; MITCHELL; AGLE; WOOD, 1997). Segundo Deegan (2002), a divulgação de informações é o melhor elemento que as companhias podem empregar para atender e gerenciar as expectativas de todos os interessados que com elas relacionam, buscando com isso obter apoio, ou para defender a sua imagem perante a sociedade. Observa-se pela perspectiva dos stakeholders que a divulgação de informações pelas companhias decorre da necessidade informacional de cada indivíduo com que ela se relaciona. Assim, a publicação dos relatórios de disclosure da sustentabilidade faz parte da estratégia organizacional que vê a necessidade de atender os anseios informativos de órgãos ligados ao meio-ambiente, a responsabilidade corporativa, e as demandas da sociedade.

Neste sentido, segundo Machado (2010), as teorias da legitimidade e dos stakeholders consideram que a empresa faz parte de um sistema social amplo, em que a divulgação de relatórios e informações que visem evidenciar práticas como responsabilidade social e sustentabilidade demonstra sua atitude transparente, bem como legitima suas ações diante da sociedade.

Por sua vez, a Teoria da Divulgação também vem sendo utilizada como base teórica em diversos estudos na área contábil. De acordo com Verrecchia (2001), a Teoria da Divulgação visa explicar o processo de divulgação de informações sob diversas perspectivas, sendo dividida em três categorias: Pesquisa sobre divulgação baseada em associação (association-based disclosore); Pesquisa sobre divulgação baseada em julgamento (discretionary-based disclosure); e Pesquisa sobre divulgação baseada em eficiência (efficiency-based disclosure).

Considerando as perspectivas da Teoria da Divulgação, o presente estudo pode ser classificado na categoria de pesquisa baseada em julgamento, pois, procurar verificar como algumas características (mecanismos) da governança corporativa adotadas pelas empresas influenciaram no disclosure da sustentabilidade corporativa por elas praticado. Segundo Salotti e Yamamoto (2005), em pesquisas baseadas em julgamento, parte-se do pressuposto que a divulgação de informações pelas companhias e um processo endógeno, sendo impactado pelas decisões internas tomadas pelos gestores e/ou pelas organizações para divulgarem essas informações. 


\section{Procedimentos Metodológicos}

O presente estudo trata-se de uma pesquisa empírico-analítica, pois busca verificar a relação do disclosure da sustentabilidade com algumas características da governança corporativa nas empresas brasileiras de capital aberto (MARTINS; THEÓPHILO, 2009). Para tanto, utilizou-se da pesquisa bibliográfica, da análise de conteúdo e de técnicas estatísticas para as avaliações necessárias.

A população desta pesquisa foi composta pelas empresas de capital aberto listadas na Bolsa de Valores, Mercadorias e Futuros do Estado de São Paulo - BM\&FBOVESPA. Já a amostra foi composta pelas empresas listadas no Índice Brasil da Bovespa (IBrX-100), que é um índice de preços que mede o retorno de uma carteira teórica formado pelas cem ações mais negociadas na BM\&FBOVESPA (BM\&FBOVESPA, 2012).

A adoção das empresas participantes do IBrX-100 como amostra da pesquisa é motivada pelo fato dessas companhias apresentarem as ações mais negociadas do mercado de capitais brasileiro, sendo assim, mais susceptíveis de atrair a atenção do investidor. Contudo, para o desenvolvimento da pesquisa foram consideradas apenas as empresas não financeiras, dado que as empresas de natureza financeira possuem características e normatização diferente das demais companhias. Esta limitação reduziu a amostra inicialmente para 82 empresas, sendo que, posteriormente, após o tratamento dos dados algumas companhias foram excluídas devido à ausência de informações para análise, reduzindo a amostra final para 76 entidades.

É importante destacar também que as empresas foram classificadas de acordo com o seu nível de governança corporativa, conforme classificação da BM\&BOVESPA, apresentando-se o nível de disclosure por cada nível de governança a que a companhia pertence.

Os dados acerca das entidades foram coletados em seus sites na internet e no software Economática ${ }^{\circledR}$. Observaram-se também as demonstrações financeiras, os relatórios corporativos, sociais e ambientais e de sustentabilidade publicados pelas companhias investigadas. Os dados são anuais, totalizando 228 observações no período de 2009 a 2011 (76 empresas em 3 anos).

\subsection{Variáveis Investigadas e Hipóteses}

\subsubsection{Variáveis dependentes}

As variáveis dependentes deste estudo foram o Nível de Disclosure da Sustentabilidade corporativa (NDS) e o Nível de Disclosure Socioambiental (NDSA). O NDS é um índice composto por um conjunto de informações econômicas, sociais e ambientais, visando contemplar informações acerca dos três pilares da sustentabilidade corporativa (aspectos econômicos, sociais e ambientais), fornecidas pelas empresas em seus relatórios corporativos, sites e demonstrativos contábeis de forma voluntária. Já o NDSA corresponde às informações socioambientais divulgadas pelas empresas em seus relatórios de sustentabilidade ou socioambiental (KOLK, 2005; MICHELON; PARBONETTI, 2012).

Para a obtenção das variáveis dependentes, utilizou-se como proxy o índice de disclosure corporativo desenvolvido por Rover e Murcia (2010), visto que este engloba os três aspectos da sustentabilidade corporativa. Este índice contempla um conjunto de 92 itens, agrupados da seguinte forma: a) informações econômicas (43); b) informações sociais (15); e, c) informações ambientais (34). Desta forma, o NDS foi composto por todas as informações contidas no índice composto por Rover e Murcia (2010) e o NDSA foi composto somente pelas informações sociais e ambientais.

Por se tratar de um índice composto por informações voluntárias, foram realizados ajustes na métrica dado que alguns itens que compunham o índice passaram a ser de divulgação obrigatória como, por exemplo, a Demonstração do Fluxo de Caixa (DFC) e a Demonstração do Valor adicionado (DVA), após a aprovação da Lei 11.938/2007 (ROVER; MURCIA, 2010). 
Assim, o nível de disclosure da sustentabilidade empresarial foi composto por 88 itens, o qual foi determinado da seguinte forma:

$$
N D S_{i} \text { ou } N D S A_{i}=\sum_{j=I}^{d} d_{j} / d
$$

Onde $N D S_{i}$ ou $N D S A_{i}$ é o nível de disclosure da sustentabilidade empresarial e socioambiental, respectivamente, da empresa $i ; d_{j}$ é o item j divulgado, que assume nota 1 quando a empresa divulga o item, e nota 0 quando item não é divulgado; $d$ é o número máximo de itens divulgados (88 itens para o NDS e 49 itens para o NDSA).

O NDS e o NDSA foram obtidos através de uma análise de conteúdo nos relatórios corporativos disponibilizados pelas empresas (demonstrações financeiras, relatórios da administração, relatórios de sustentabilidade, e nos sites das companhias na internet), buscando identificar se as companhias divulgavam as informações que faziam parte do índice. Contudo, ressalta-se que o índice desenvolvido por Rover e Murcia (2010) é passível de algumas críticas, como por exemplo, a maioria dos itens que compõem o índice é de natureza econômicofinanceira. Além disso, não há um critério de ponderação paras as informações que compõem a métrica, ou seja, todas as informações divulgadas apresentam o mesmo peso na constituição do índice.

Apesar destas criticas, conforme Rover e Murcia (2010) por se tratar de uma métrica constituída a partir de estudos anteriores e da teoria existente minimizam-se a subjetividade e, consequentemente, o viés na escolha das variáveis que compõem o índice. Ademais, o citado índice contempla informações acerca dos três aspectos da sustentabilidade corporativa, quais sejam econômicas, sociais e ambientais.

\subsubsection{Variáveis explicativas e hipóteses}

a) Dualidade do CEO (CEO). Estudos realizados acerca da influência da ocupação dos cargos de Diretor Executivo e Presidente do Conselho de Administração por pessoas diferentes não são conclusivos quanto ao efeito desta separação no disclosure empresarial (HO; WONG, 2001; CHENG; COURTENAY, 2006). Já Gul e Leung (2004) encontraram uma associação negativa com a ocupação por pessoas diferentes nos cargos de presidente do conselho de administração com o da diretoria executiva em um estudo realizado com empresas de Hong Kong. Desta forma, apresenta-se a seguinte hipótese de pesquisa:

Hipótese 1: A ocupação dos cargos de Diretor Executivo e de Presidente do Conselho de Administração por diretores diferentes influencia o disclosure da sustentabilidade empresarial praticado pelas companhias investigadas.

Para mensurar a influência da ocupação dos cargos de Diretor Executivo e Presidente do Conselho por pessoas diferentes utilizou-se uma variável dummy, que assume valor 1 se o cargo de presidente do conselho de administração é ocupado por um diretor que não o diretorpresidente da diretoria executiva, e valor 0 caso contrário.

b) Nível de Governança Corporativa (GOV). A adoção de boas práticas de governança corporativa pelas empresas tem como objetivo reduzir o nível de assimetria informacional que possa existir entre o principal e o agente. Dentre os mecanismos utilizados pela governança corporativa para mitigar esse problema destaca-se o disclosure de informações. Segundo Adams (2002), a adoção de bons mecanismos de governança corporativa aumenta o disclosure de informações econômicas e socioambientais por parte das companhias. Ainda, de acordo com Iatrides (2013), a qualidade da informação ambiental divulgada pelas companhias é influenciada pelas práticas de governança corporativa adotadas pelas firmas. Neste sentido, 
considerando que a BM\&FBOVESPA possui uma classificação das empresas quanto ao nível de governança adotado pelas companhias, tomando-se o Novo Mercado como referência, elaborou-se a seguinte hipótese de pesquisa:

Hipótese 2: A participação das companhias em níveis diferenciados de governança corporativa influencia no disclosure da sustentabilidade por elas praticado.

Para identificar o nível de governança a que a empresa pertencia, empregou-se uma variável dummy que assume valor igual a 1 se a firma se enquadra no Novo Mercado de governança corporativa da BM\&FBOVEPA, e 0 caso contrário.

c) Comitê de sustentabilidade (Comitê). Estudos apontam que um conselho ou comitê de responsabilidade corporativa ou de sustentabilidade influência de maneira positiva no disclosure e na implementação de ações voltadas a sustentabilidade corporativa, pois seus dirigentes atuam de forma a demonstrar para os stakeholders que a companhia se preocupa com o meio-ambiente e o bem estar de toda a sociedade (ULLMAN, 1985; ZAHRA; PEARCE, 1989; MICHELON; PARBONETTI, 2012). Sendo assim, apresenta-se a seguinte hipótese de pesquisa:

Hipótese 3: A presença de um comitê de sustentabilidade na estrutura de administração das empresas influencia no disclosure da sustentabilidade por elas praticado.

A presença de um comitê de sustentabilidade ou responsabilidade social corporativa é mensurada através de uma variável dicotômica, que assume valor igual a 1 se a empresa possui tal órgão, e 0 caso contrário.

d) Diretores independentes (DirInd). Diretores independentes são pessoas que participam no conselho de administração das companhias, mas que não mantém relação empregatícia com a mesma, nem foram diretores das entidades em períodos anteriores e que não possuem algum vínculo familiar com os administradores da companhia. A participação de diretores independentes no conselho de administração das companhias é visto como fator para o aumento na divulgação de informações para os investidores e demais interessados nas empresas (ENG; MAK, 2003). Alguns estudos encontraram uma relação positiva entre a proporção de diretores independentes e a divulgação de informações financeiras pelas empresas (CHEN; JAGGI, 2000; MICHELON; PARBONETTI, 2012). Por outro lado, Eng e Mak (2003) reportaram uma associação negativa entre o aumento de diretores independentes e o disclosure corporativo. Desta forma, considerando o reportado acima, apresenta-se a seguinte hipótese de pesquisa:

Hipótese 4: A presença de diretores independentes no conselho de administração das companhias influencia no disclosure da sustentabilidade por elas praticado.

A presença de diretores independentes é mensurada através de uma variável dicotômica, que assume valor igual a 1 se há diretores independentes no conselho de administração, e 0 caso contrário.

e) Influência da comunidade (InfCom). A participação de diretores independentes no conselho de administração das empresas é visto como um link entre a entidade e o ambiente externo em que esta inserida, pois através destes diretores busca-se legitimar as ações da companhia frente aos seus stakeholders (HILLMAN; CANNELLA JR; PAETZOLD, 2000; MICHELON; PARBONETTI, 2012). Michelon e Parbonetti (2012) evidenciam que membros da comunidade que participam no conselho de administração das empresas como políticos aposentados, diretores de órgãos governamentais, professores universitários e membros de 
fundações sociais ou ambientais podem servir intermediários das expectativas da comunidade acerca das atividades desenvolvidas pelas empresas em seu benefício, encontrando em seu estudo uma relação positiva com a divulgação da sustentabilidade. Neste sentido, apresenta-se a seguinte hipótese de pesquisa:

Hipótese 5: A participação de diretores ligados a comunidade (sociedade) no conselho de administração das empresas influencia no disclosure da sustentabilidade por elas praticado.

A participação de diretores ligados a comunidade foi mensurado através de uma variável dicotômica, que assume valor igual a 1 se há diretores que participem de organizações sociais ou ambientais, professores universitários, políticos aposentados, entre outros, no conselho de administração da companhia, e 0 caso contrário. Para tanto, observou-se o Curriculum dos diretores disponibilizados pelas companhias em seus sites na internet e/ou nos relatórios corporativos.

f) Board interlocking (PartOut). Quando um membro de um conselho de administração de uma companhia ocupa o cargo de diretor no conselho de administração de outra empresa, surge o fenômeno do board interlocking (ALLEN, 1974; MIZRUCHI, 1996). Segundo Dooley (1969), a presença de diretores comuns nas companhias força a gestão da entidade a considerar os interesses da comunidade em termos de crescimento econômico, social e político, ensejando que ela adote práticas que visem o bem-estar da sociedade. Para Davis (1996) a presença de diretores comuns no conselho de administração de várias empresas é uma faceta da relação social em que a companhia esta envolvida, que incorpora na governança corporativa uma rede de informações, onde esses diretores fornecem um mecanismo para legitimar essas organizações e expandir seus negócios. Neste sentido, considerando que o disclosure da sustentabilidade visa legitimar as ações desenvolvidas pelas organizações frente aos seus interessados, apresenta-se a seguinte hipótese de pesquisa:

Hipótese 6: A presença de diretores comuns, que participam no conselho de administração de mais de uma empresa, influencia no disclosure da sustentabilidade empresarial das companhias investigadas.

A participação de diretores comuns entre as empresas foi mensurado através de uma variável dicotômica, que assume valor igual a 1 se há diretores que participem do conselho de administração de mais de uma companhia, e 0 caso contrário.

g) Administração Familiar (AdmFam). São consideradas empresas familiares aquelas em que a maioria dos membros da família fundadora continua ocupando os principais cargos executivos da administração, participando do conselho de administração, da diretoria executiva e nos demais cargos da administração (CHEN et al., 2010; PAULO; CAVALCANTE, 2012). Os diferentes conceitos de empresas familiares encontrados na literatura convergem em caracterizar uma empresa familiar como uma organização onde a gestão do negócio está vinculada aos membros familiares. No que tange a divulgação voluntária de informações por parte das empresas administrados por familiares, de acordo com Chen, Chen e Cheng (2008) e Darmadi e Sodikin (2013), as empresas familiares tendem a divulgar menos informações voluntárias do que as outras companhias, uma vez que há menos transparência em suas práticas de governança corporativa. Desta forma, considerando que em empresas administradas ou controladas por membros de uma família tendem a divulgar menos informações do que as outras organizações apresenta-se a seguinte hipótese de pesquisa: 
Hipótese 7: A presença de membros familiares na administração das companhias influencia no disclosure da sustentabilidade por elas praticado.

A participação de membros familiares na administração da empresa foi mensurada através de uma variável dummy, que assume valor igual a 1 se a companhia possui características de empresa familiar, como por exemplo, membros familiares no conselho de administração e na diretoria executiva da organização, e 0 caso contrário. Para identificar se a corporação apresentava características familiares observou-se nos relatórios corporativos e no site das companhias o seu histórico, e observaram-se também as informações sobre cada membro do conselho de administração e da diretoria executiva nos informes e relatórios da administração disponibilizados na internet.

\subsubsection{Variáveis de controle}

As variáveis de controle utilizadas tiveram como base a literatura sobre o tema. Alguns estudos demonstram que o tamanho das empresas tem associação positiva com o nível de disclosure, de forma que quanto maior o tamanho da companhia mais informações ela divulga (KELLY, 1981; TROTMAN; BRADLEY, 1981; HACKSTON; MILNE 1996). Esta variável de controle foi mensurada pelo logaritmo do ativo total das empresas. Outra variável que também tem sido identificada como possível fator para o disclosure corporativo é a idade ou tempo de atuação das companhias (HANIFFA; COOKE, 2002). Esta variável foi mensurada através dos anos de atuação da firma no mercado, isto é, do período de sua abertura até o interstício desta pesquisa. Com relação ao desempenho, de acordo com a literatura espera-se que quanto melhor o desempenho da companhia maior seja o seu disclosure (VERRECHIA, 2001; SALOTTI; YAMAMOTO, 2005). A proxy empregada para representar essa variável foi retorno sobre o patrimônio líquido - ROE (HACKSTON; MILNE, 1996; WILLIAMS 1999). Por fim, também se utilizou o risco da empresa que foi representado pelo beta e refere-se ao risco inerente a um ativo (ROVER; MURCIA, 2010). Para tal, utilizou-se o beta da empresa calculado através do Economática ${ }^{\circledR}$, considerando-se um período de 60 meses para representar o risco sistemático.

\subsection{Modelo Econométrico}

Para testar a relação entre o nível de disclosure da sustentabilidade empresarial e as características da governança corporativa, e com algumas características das empresas, foi empregado um modelo de regressão com dados em painel efeitos fixos e aleatórios. Para tanto, adaptou-se o modelo econométrico empregado por Michelon e Parbonetti (2012), descrevendoo da seguinte forma:

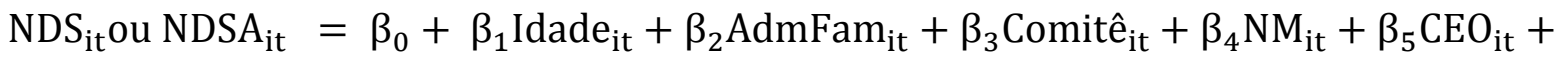
$\beta_{6}$ DiretInd $_{\text {it }}++\beta_{7}$ ISE $_{\text {it }}+\beta_{8}$ InfCom $_{\text {it }}+\beta_{9}$ PartOut $_{\text {it }}+\beta_{10}$ Tamanho $_{\text {it }}+\beta_{11}$ Beta $_{\text {it }}+$ $\mathrm{ROE}_{i \mathrm{it}}+\varepsilon_{\mathrm{it}}$

Onde, $N D S_{i t}$ é a variável dependente que representa o nível de disclosure da sustentabilidade empresarial da empresa $i$ no período $t$; e, NDSA ${ }_{i t}$ é o nível de disclosure socioambiental da companhia $i$ no período $t$. As variáveis explicativas são: Idade (representada pelo tempo de atuação da companhia no mercado), AdmFam (variável que representa se a companhia investigada apresenta características de empresas familiares, assumido valor 1 se a firma é familiar, e 0 caso contrário), Comitê (assume valor 1 se a companhia apresenta comitê ou órgão de sustentabilidade, e 0 caso contrário), $N M$ (assume valor 1 se a organização está no Novo Mercado da BM\&FBOVESPA, e 0 caso contrário), $C E O$ (assume valor 1 se o CEO não é o 
presidente do conselho de administração, e 0 caso contrário), DiretInd (assume valor 1 se a companhia apresenta diretores independentes em seu conselho de administração, e 0 caso contrário), InfCom (assume valor 1 se há diretores no conselho da administração que são políticos, professores de universidade ou diretores de organizações sociais ou ambientais, e 0 caso contrário), PartOut (assume valor 1 se há conselheiros da companhia que participam do conselho de administração de outras empresas, e valor 0 caso contrário), Tamanho (representado pelo logaritmo do ativo total de cada empresa), Beta (risco de mercado da empresa) e $R O E$ (indica o desempenho da empresa no período). $\mathcal{E}_{i t}$ é o erro da regressão.

\section{DESCRIÇÃO E ANÁLISE DOS RESULTADOS}

\subsection{Estatísticas Descritivas}

A Tabela 1 apresenta as estatísticas descritivas das variáveis investigadas na pesquisa. Como dito na metodologia, formou-se um painel balanceado de observações das 76 empresas ao longo de três anos, perfazendo um total de 228 observações no período. As empresas foram agrupadas de acordo com o nível de governança corporativa adotado. O índice disclosure da sustentabilidade empresarial (NDS) e o índice de divulgação de informações socioambientais (NDSA), bem com as variáveis explicativas foram analisados por cada nível de governança corporativa.

Tabela 1 - Estatística descritiva das variáveis - 2009 a 2011.

\begin{tabular}{|c|c|c|c|c|c|c|c|c|c|c|}
\hline \multirow{2}{*}{ Variáveis } & \multicolumn{5}{|c|}{ Mercado Tradicional } & \multicolumn{5}{|c|}{ Nível 1} \\
\hline & Obs. & Média & Sd. & Mín. & Máx. & Obs. & Média & Sd. & Mín. & Máx. \\
\hline NDSA & 39 & 0,33 & 0,16 & 0,02 & 0,89 & 39 & 0,39 & 0,08 & 0,22 & 0,50 \\
\hline NDS & 39 & 0,66 & 0,22 & 0,22 & 0,97 & 39 & 0,75 & 0,12 & 0,49 & 0,90 \\
\hline Idade & 39 & 23,38 & 15,46 & 3,00 & 45,00 & 39 & 37,18 & 10,82 & 5,00 & 45,00 \\
\hline Comitê & 39 & 0,67 & 0,48 & 0,00 & 1,00 & 39 & 0,74 & 0,44 & 0,00 & 1,00 \\
\hline AdmFam & 39 & 0,23 & 0,43 & 0,00 & 1,00 & 39 & 0,46 & 0,51 & 0,00 & 1,00 \\
\hline CEO & 39 & 0,67 & 0,48 & 0,00 & 1,00 & 39 & 1,00 & 0,00 & 1,00 & 1,00 \\
\hline DiretInd & 39 & 0,59 & 0,50 & 0,00 & 1,00 & 39 & 0,49 & 0,51 & 0,00 & 1,00 \\
\hline InfCom & 39 & 0,51 & 0,51 & 0,00 & 1,00 & 39 & 0,69 & 0,47 & 0,00 & 1,00 \\
\hline PartOut & 39 & 0,74 & 0,44 & 0,00 & 1,00 & 39 & 0,79 & 0,41 & 0,00 & 1,00 \\
\hline Tamanho & 39 & 16,07 & 1,24 & 13,22 & 18,00 & 39 & 17,29 & 1,45 & 14,30 & 20,21 \\
\hline Beta & 39 & 0,45 & 0,59 & $-0,44$ & 10,47 & 39 & 0,88 & 0,41 & 0,00 & 10,50 \\
\hline ROE & 39 & 0,28 & 0,30 & $-0,21$ & 10,56 & 39 & 0,11 & 0,08 & $-0,05$ & 0,27 \\
\hline \multirow{2}{*}{ Variáveis } & \multicolumn{5}{|c|}{ Nível 2} & \multicolumn{5}{|c|}{ Novo Mercado } \\
\hline & Obs. & Média & Sd. & Mín. & Máx. & Obs. & Média & Sd. & Mín. & Máx. \\
\hline NDSA & 12 & 0,38 & 0,08 & 0,24 & 0,49 & 136 & 0,29 & 0,14 & 0,00 & 0,51 \\
\hline NDS & 12 & 0,75 & 0,12 & 0,53 & 0,88 & 136 & 0,61 & 0,20 & 0,10 & 0,93 \\
\hline Idade & 12 & 23,25 & 19,18 & 3,00 & 45,00 & 136 & 20,02 & 15,73 & 0,25 & 58,00 \\
\hline Comitê & 12 & 0,83 & 0,39 & 0,00 & 1,00 & 136 & 0,53 & 0,50 & 0,00 & 1,00 \\
\hline AdmFam & 12 & 0,50 & 0,52 & 0,00 & 1,00 & 136 & 0,43 & 0,50 & 0,00 & 1,00 \\
\hline CEO & 12 & 0,58 & 0,51 & 0,00 & 1,00 & 136 & 0,74 & 0,44 & 0,00 & 1,00 \\
\hline DiretInd & 12 & 1,00 & 0,00 & 1,00 & 1,00 & 136 & 0,84 & 0,37 & 0,00 & 1,00 \\
\hline InfCom & 12 & 0,50 & 0,52 & 0,00 & 1,00 & 136 & 0,54 & 0,50 & 0,00 & 1,00 \\
\hline PartOut & 12 & 0,50 & 0,52 & 0,00 & 1,00 & 136 & 0,82 & 0,39 & 0,00 & 1,00 \\
\hline Tamanho & 12 & 15,60 & 0,59 & 14,73 & 16,29 & 136 & 15,54 & 1,20 & 8,44 & 17,67 \\
\hline Beta & 12 & 0,81 & 0,56 & 0,00 & 10,51 & 136 & 0,93 & 0,95 & $-0,57$ & 30,66 \\
\hline ROE & 12 & 0,18 & 0,20 & $-0,34$ & 0,39 & 136 & 0,19 & 0,29 & $-0,36$ & 10,78 \\
\hline
\end{tabular}

Fonte: Economática, relatórios corporativos e sites das empresas.

Bomfim, E. T.; Teixeira, W. S.; Monte, P. A. 
De acordo com os dados expostos na Tabela 1, observa-se que as empresas do Nível 1 e do Nível 2 de governança corporativa apresentaram a maior média de disclosure da sustentabilidade (NDS) entre as empresas analisadas $(0,75)$, superior às empresas dos demais níveis de governança, principalmente, as do Novo Mercado que, devido a adoção desses níveis, submetem-se a mais transparência na divulgação de informações corporativas. Observa-se também que as empresas do Nível 1 foram as que mais divulgarem informações socioambientais (NDSA) entre as empresas analisadas (0,39), superando as demais companhias analisadas. Além disso, as empresas do Novo Mercado foram as que apresentaram o menor índice na divulgação do disclosure da sustentabilidade $(0,10)$ e socioambiental $(0,00)$, enquanto isso, as entidades do Mercado Tradicional foram as que apresentaram o maior nível de divulgação de informações (NDS $=0,97$ ) e de informações socioambientais (NDSA $=0,89$ ), mostrando que apesar de não adotarem práticas diferenciadas de governança corporativa buscam demonstrar para os seus stakeholders suas ações e projetos no que se refere à sustentabilidade empresarial. É importante destacar que a maioria das informações que compõem a métrica do NDS não é legalmente obrigatória, o que reforça a importância do alto índice alcançado por algumas empresas (cerca de 10\% da amostra apresentou um NDS superior a 0,82 ).

A média de idade das empresas pesquisadas, conforme Tabela 1, varia entre 20 e 37 anos, aproximadamente. No que respeita os níveis de governança corporativa, a análise descritiva permite observar que a maioria das empresas pertencem ao Novo Mercado da BM\&FBOVESPA, seguidas pelas empresas do Nível 1, Mercado Tradicional e Nível 2, respectivamente.

A análise descritiva também demonstra que, em média, 83\% das empresas do Nível 2 apresentam um comitê de sustentabilidade em sua estrutura corporativa, seguidas pelas do Nível 1 (74\%), Mercado Tradicional (67\%), e Novo Mercado (53\%), demonstrando a relevância desse órgão na estrutura corporativa dessas empresas. E, com relação ao tamanho das empresas, os dados revelam uma variação média de 15,54 a 17,29 entre as empresas dos quatro níveis de governança.

\subsection{Análise dos Resultados Econométricos}

Depois de uma breve análise descritiva, o passo seguinte foi à estimação dos modelos econométricos. Inicialmente, para se determinar corretamente o modelo a ser estimado foram feitos testes econométricos, dentre os quais o teste de Chow, o de Hausman e o de Wald. Iniciando pelo teste de Chow, cujo objetivo é testar de forma conjunta se as variáveis dicotômicas anuais são estatisticamente iguais a zero (Teste de Chow: $\mathrm{F}=12,18$; Prob> $\mathrm{F}=0,0000$ ). Os resultados rejeitam a hipótese nula, indicando, portanto, que o modelo de efeitos fixos é preferível ao modelo com dados empilhados (pooled).

O segundo teste aplicado (teste de Hausman) teve como objetivo a escolha entre os modelos de efeitos fixos e o de efeitos aleatórios (Teste de Hausman: Prob>Chi2=0.0641). Os resultados demonstraram que ao nível de 5\% de significância rejeita-se a hipótese nula, indicando que o modelo de efeitos fixos é preferível ao de efeitos aleatórios. Contudo, caso seja aceito um nível de $10 \%$ de significância, o modelo a ser considerado seria o de efeitos aleatórios. Por isso, estimaram-se os dois tipos de dados em painel, modelos de efeitos fixos e aleatórios (Tabela 2 e Tabela 3). Por fim, aplicou-se o teste de Wald (teste de detecção de heterocedasticidade para efeitos fixos) que rejeitou a hipótese nula de ausência de heterocedasticidade (Teste de Wald: Prob>chi2=0,0000). Dessa forma, o modelo foi aplicado em sua forma robusta para correção de heterocedasticidade.

A Tabela 2 apresenta os resultados para os seis modelos de efeitos fixos estimados. $\mathrm{O}$ primeiro modelo estima o nível de disclosure da sustentabilidade (NDS) em relação a variável Relação entre o Disclosure da Sustentabilidade com a Governança Corporativa: Um Estudo nas Empresas... 
empresas administradas por familiares (AdmFam) e idade das empresas no mercado (Modelo 1). Nos modelos 2 e 3 são incluídas as demais variáveis relacionadas à governança corporativa (Modelo 2), e a situação econômico-financeira da empresa (Modelo 3). Ressalta-se, porém, que a variável de controle beta e a variável de governança (NM) foram excluídas por terem apresentado multicolinearidade. Já os modelos 4, 5 e 6 mostram os resultados em relação a variável dependente nível de disclosure das informações socioambientais (NDSA).

Analisando-se os resultados expostos na Tabela 2, a seguir, verifica-se no Modelo 1 que o nível de disclosure da sustentabilidade (NDS) parece ser influenciado pelo tempo de atuação dessas companhias no mercado, sendo estatisticamente significante ao nível de $1 \%$. Esse resultado sugere que quanto mais tempo a organização está no mercado ela tende a divulgar mais informações econômicas e socioambientais. Tal resultado está de acordo com o estudo Haniffa e Cooke (2002) que encontraram uma relação positiva entre a divulgação de informações econômicas e sociais pelas empresas e o tempo de participação dessas companhias no mercado.

A variável administração familiar (AdmFam), conforme Tabela 2,que identifica a relação entre as empresas administrados por familiares e o nível de disclosure da sustentabilidade, também apresentou uma relação positiva com a variável dependente, sendo estatisticamente significante ao nível de $1 \%$. Esse resultado difere do reportado pela literatura (CHEN; CHEN; CHENG, 2008; DARMADI; SODIKIN, 2013), sugerindo que as empresas com características familiares tendem a divulgar mais informações do que as outras companhias.

Tabela 2 - Resultados da regressão com dados em painel - modelos efeitos-fixos - 2009 a 2011.

\begin{tabular}{|c|c|c|c|c|c|c|}
\hline \multirow{2}{*}{$\begin{array}{l}\text { Variáveis } \\
\text { Explicativas }\end{array}$} & \multicolumn{3}{|c|}{ Variável Dependente: NDS } & \multicolumn{3}{|c|}{ Variável Dependente: NDSA } \\
\hline & Modelo 1 & Modelo 2 & Modelo 3 & Modelo 4 & Modelo 5 & Modelo 6 \\
\hline Idade & $\begin{array}{c}\mathbf{0 . 0 3 5 4} * * * \\
(0.0066)\end{array}$ & $\begin{array}{c}\mathbf{0 . 0 3 5 0} * * * \\
(0.0081)\end{array}$ & $\begin{array}{c}\mathbf{0 . 0 2 5 8} * * * \\
(0.0086)\end{array}$ & $\begin{array}{c}\mathbf{0 . 0 1 6 7} * * * \\
(0.0060)\end{array}$ & $\begin{array}{l}\mathbf{0 . 0 1 3 3 *} \\
(0.0072)\end{array}$ & $\begin{array}{l}\mathbf{0 . 0 1 3 3 *} \\
(0.0069)\end{array}$ \\
\hline AdmFam & $\begin{array}{c}\mathbf{0 . 0 3 7 8} * * * \\
(0.0100)\end{array}$ & $\begin{array}{c}\mathbf{0 . 0 3 8 5} * * * \\
(0.0121)\end{array}$ & $\begin{array}{c}\mathbf{0 . 0 6 0 6} * * * * \\
(0.0148)\end{array}$ & $\begin{array}{c}0.0033 \\
(0.0090)\end{array}$ & $\begin{array}{c}0.0085 \\
(0.0108)\end{array}$ & $\begin{array}{c}0.0227 \\
(0.0151)\end{array}$ \\
\hline Comitê & & $\begin{array}{l}-0.0039 \\
(0.0270)\end{array}$ & $\begin{array}{l}-0.0026 \\
(0.0272)\end{array}$ & & $\begin{array}{c}0.0080 \\
(0.0247)\end{array}$ & $\begin{array}{c}0.0032 \\
(0.0245)\end{array}$ \\
\hline CEO & & $\begin{array}{c}0.0023 \\
(0.0330)\end{array}$ & $\begin{array}{c}0.0069 \\
(0.0339)\end{array}$ & & $\begin{array}{c}0.0226 \\
(0.0328)\end{array}$ & $\begin{array}{c}0.0236 \\
(0.0345)\end{array}$ \\
\hline DiretInd & & $\begin{array}{c}0.0374 \\
(0.0266)\end{array}$ & $\begin{array}{c}0.0411 \\
(0.0280)\end{array}$ & & $\begin{array}{c}0.0278 \\
(0.0189)\end{array}$ & $\begin{array}{l}\mathbf{0 . 0 3 3 2} * \\
(0.0199)\end{array}$ \\
\hline InfCom & & $\begin{array}{c}0.0345 \\
(0.0275)\end{array}$ & $\begin{array}{c}0.0414 \\
(0.0293)\end{array}$ & & $\begin{array}{c}\mathbf{0 . 0 6 0 9} * * \\
(0.0285)\end{array}$ & $\begin{array}{c}\mathbf{0 . 0 7 0 9} * * \\
(0.0324)\end{array}$ \\
\hline PartOut & & $\begin{array}{l}-0.0108 \\
(0.0159)\end{array}$ & $\begin{array}{l}-0.0096 \\
(0.0175)\end{array}$ & & $\begin{array}{l}-0.0234 \\
(0.0168)\end{array}$ & $\begin{array}{l}-0.0232 \\
(0.0176)\end{array}$ \\
\hline Tamanho (LnAtivos) & & & $\begin{array}{c}\mathbf{0 . 0 3 8 8} * * * \\
(0.0092)\end{array}$ & & & $\begin{array}{l}\mathbf{0 . 0 1 3 0} * \\
(0.0075)\end{array}$ \\
\hline ROE & & & 0.0591 & & & 0.1239 \\
\hline Constante & $\begin{array}{l}-0.2075 \\
(0.1537)\end{array}$ & $\begin{array}{l}-0.2357 \\
(0.1647)\end{array}$ & $\begin{array}{c}(0.0465) \\
\mathbf{- 0 . 6 6 8 4} * * * \\
(0.1667)\end{array}$ & $\begin{array}{l}-0.0808 \\
(0.1383)\end{array}$ & $\begin{array}{l}-0.0594 \\
(0.1443)\end{array}$ & $\begin{array}{c}(0.0826) \\
\mathbf{- 0 . 3 0 3 8} * * \\
(0.1226)\end{array}$ \\
\hline Observações & 226 & 226 & 226 & 226 & 226 & 226 \\
\hline
\end{tabular}

Nota: (1) Erros padrões em parênteses. 2) Significância estatística: *p<0,10; **p<0,05;***p<0,01.

Com relação ao segundo modelo (Modelo 2), apresentam-se os resultados após a inclusão das outras variáveis relativas a estrutura da governança corporativa. Apesar da inclusão dessas outras variáveis, os resultados demonstram que apenas a variável Idade das empresas Bomfim, E. T.; Teixeira, W. S.; Monte, P. A. 
possui uma relação direta com o nível de disclosure da sustentabilidade. Todavia, nenhuma das variáveis que caracterizam aspectos da governança corporativa parece influenciar na divulgação de informações econômicas e socioambientais pelas empresas analisadas.

No Modelo 3, incluiu-se as variáveis relativas ao tamanho das companhias, medido pelo logaritmo natural do ativo total, e o desempenho (ROE). Os resultados da estimação demonstram mais uma vez que a idade das empresas apresenta uma forte relação com a divulgação de informações econômicas e socioambientais pelas empresas, apresentando-se estatisticamente significante ao nível de 1\%. A variável que identifica as empresas que são consideradas familiares (AdmFam) também voltou a mostrar relação com o disclosure da sustentabilidade, sugerindo que as empresas familiares estão divulgando mais este tipo de informações do que as outras companhias, diferindo mais uma vez do reportado pela literatura (CHEN; CHEN; CHENG, 2008; DARMADI; SODIKIN, 2013).

Sobre as demais variáveis incluídas no modelo, observou-se que apenas a variável tamanho apresentou uma relação positiva e estatisticamente significante ao nível de $1 \%$. Tal resultado indica que empresas de maior porte são mais propensas a divulgar informações econômicas e socioambientais do que organizações de porte menor, conforme relatado pela literatura (KELLY, 1981; TROTMAN; BRADLEY, 1981; HACKSTON; MILNE 1996).

No que se refere aos modelos 4, 5 e 6 que considera a variável nível de disclosure socioambiental (NDSA) como variável dependente, observou-se que nos três modelos a variável Idade das companhias apresentou-se estatisticamente significante ao nível de $1 \%$ e $10 \%$, respectivamente, corroborando e demonstrando que o tempo das empresas no mercado influencia no disclosure corporativo relativo às informações socioambientais, conforme evidenciado em outros estudos (HANIFFA; COOKE, 2002; HANIFFA; COOKE, 2005). No tocante as demais variáveis, os resultados apresentados denotam que a participação de diretores independentes (DiretInd) no conselho de administração influencia na divulgação de informações socioambientais pelas companhias, conforme sugerido por Chen e Jaggi (2000), Eng e Mak (2003) e Michelon e Parbonetti (2012), demonstrando que a participação destes diretores no conselho da administração proporciona maior divulgação de informações socioambientais pelas firmas.

A variável participação de membros da comunidade no conselho de administração das firmas (InfCom) parece influenciar no disclosure de informações socioambientais, apresentando-se estatisticamente significante ao nível de $5 \%$ nos modelos 5 e 6 , consoante ao sugerido nos estudos de Hillman, Cannella Jr. e Paetzold (2000) e Michelon e Parbonetti (2012). Este resultado demonstra o quanto as empresas buscam demonstrar para a sociedade sua preocupação e sua responsabilidade para com as questões sociais e ambientais, visando manter um canal de comunicação com a comunidade.

Ainda observou-se que a variável tamanho também apresentou uma relação positiva com a disclosure de informações socioambientais no modelo 6, contudo, significante ao nível de $10 \%$. Mais uma vez esse resultado corrobora com os outros relatados anteriormente, demonstrando que há relação entre a divulgação de informações pelas empresas e seu tamanho, conforme sugerido pela literatura.

A seguir, na Tabela 3, apresentam-se os resultados obtidos para as variáveis dependentes (NDS e NDSA), considerando os modelos de dados em painel com efeitos aleatórios. 
Sociedade, Contabilidade e Gestão, Rio de Janeiro, v. 10, n. 1, jan/abr 2015.

Tabela 3 - Resultado da regressão com dados em painel - modelo efeitos aleatórios - 2009 a 2011.

\begin{tabular}{|c|c|c|c|c|c|c|}
\hline \multirow{2}{*}{ Variáveis Explicativas } & \multicolumn{3}{|c|}{ Variável Dependente: NDS } & \multicolumn{3}{|c|}{ Variável Dependente: NDSA } \\
\hline & Modelo 7 & Modelo 8 & Modelo 9 & Modelo 10 & Modelo 11 & Modelo 12 \\
\hline \multirow[t]{2}{*}{ Idade } & $0.0046 * * *$ & $0.0029 * *$ & 0.0017 & $0.0022 * *$ & 0.0010 & 0.0004 \\
\hline & $(0.0013)$ & $(0.0013)$ & $(0.0012)$ & $(0.0009)$ & $(0.0009)$ & $(0.0009)$ \\
\hline \multirow[t]{2}{*}{ AdmFam } & -0.0339 & -0.0276 & -0.0079 & -0.0237 & -0.0157 & -0.0014 \\
\hline & $(0.0408)$ & $(0.0383)$ & $(0.0361)$ & $(0.0286)$ & $(0.0271)$ & $(0.0265)$ \\
\hline \multirow[t]{2}{*}{ Comitê } & & $0.0571 * * *$ & $0.0393 * *$ & & $0.0399 * * *$ & $0.0301 * *$ \\
\hline & & $(0.0192)$ & $(0.0186)$ & & $(0.0150)$ & $(0.0148)$ \\
\hline \multirow[t]{2}{*}{ NM } & & -0.0640 & -0.0293 & & $-0.0527 *$ & -0.0355 \\
\hline & & $(0.0433)$ & $(0.0410)$ & & $(0.0302)$ & $(0.0297)$ \\
\hline \multirow[t]{2}{*}{ CEO } & & 0.0398 & 0.0316 & & 0.0348 & 0.0307 \\
\hline & & $(0.0279)$ & $(0.0265)$ & & $(0.0214)$ & $(0.0207)$ \\
\hline \multirow[t]{2}{*}{ DiretInd } & & 0.0118 & 0.0254 & & 0.0123 & 0.0227 \\
\hline & & $(0.0258)$ & $(0.0247)$ & & (0.0199) & (0.0194) \\
\hline \multirow[t]{2}{*}{ InfCom } & & 0.0501 & 0.0209 & & $0.0471 * *$ & 0.0365 \\
\hline & & $(0.0315)$ & $(0.0304)$ & & $(0.0236)$ & $(0.0234)$ \\
\hline \multirow[t]{2}{*}{ PartOut } & & 0.0119 & 0.0141 & & -0.0069 & -0.0043 \\
\hline & & (0.0399) & $(0.0376)$ & & $(0.0295)$ & $(0.0286)$ \\
\hline \multirow[t]{2}{*}{ Tamanho (LnAtivos) } & & & $0.0555 * * *$ & & & $0.0286 * * *$ \\
\hline & & & $(0.0107)$ & & & $(0.0084)$ \\
\hline \multirow[t]{2}{*}{ ROE } & & & 0.0274 & & & $0.0846 * * *$ \\
\hline & & & $(0.0373)$ & & & $(0.0295)$ \\
\hline \multirow[t]{2}{*}{ Constante } & $0.5525 * * *$ & $0.5176 * * *$ & $-0.3519 * *$ & $0.2754 * * *$ & $0.2512 * * *$ & -0.2178 \\
\hline & $(0.0400)$ & $(0.0601)$ & $(0.1787)$ & $(0.0275)$ & $(0.0431)$ & $(0.1386)$ \\
\hline Observações & 226 & 226 & 226 & 226 & 226 & 226 \\
\hline
\end{tabular}

Os resultados expostos na Tabela 3 referem-se aos coeficientes estimados para os outros seis modelos, considerando o modelo de dados em painel com efeitos aleatórios. No Modelo (7), observa-se que a variável Idade continua apresentando uma relação positiva e significante ao nível de $1 \%$ com o disclosure da sustentabilidade praticado pelas empresas pesquisadas. Contudo, a variável administração familiar (AdmFam), considerando os efeitos aleatórios, não apresentam significância estatística.

Por sua vez, no Modelo 8 foram incluídas novamente as outras variáveis acerca dos aspectos da estrutura da governança corporativa. As evidencias mostram novamente a Idade das firmas apresenta-se estatisticamente significante ao nível de 5\%, demonstrando que o tempo de mercado das empresas influencia no disclosure corporativo. Os resultados ainda apontam que a presença de um comitê de sustentabilidade nas empresas impacta positivamente no disclosure da sustentabilidade empresarial, mostrando-se estatisticamente significante ao nível de 5\%. Esta constatação está em consonância com o relatado na literatura, que prevê a influencia desses órgãos na divulgação e implementação das práticas desenvolvidas pelas corporações em prol da sociedade e na preservação do meio-ambiente (ULLMAN, 1985; ZAHRA; PEARCE, 1989; ADAMS, 2002; MICHELON; PARBONETTI, 2012).

No Modelo 9, observa-se novamente que a variável Comitê apresenta-se estatisticamente significante ao nível de 5\%, relacionando-se positivamente com a divulgação de informações pelas companhias, conforme estudos anteriores (ULLMAN, 1985; ZAHRA; PEARCE, 1989; ADAMS, 2002; MICHELON; PARBONETTI, 2012). Outra variável que apresentou significância estatística foi o Tamanho das empresas, significante ao nível de $1 \%$, evidenciando uma associação positiva entre o tamanho das organizações e o nível de disclosure por elas praticado (KELLY, 1981; TROTMAN; BRADLEY, 1981; HACKSTON; MILNE 1996). 
Nas demais regressões (Modelos 10, 11 e 12), observou-se a influência das variáveis explicativas, considerando como variável dependente apenas o disclosure socioambiental praticado pelas firmas (NDSA), estimando-os com dados em painel na sua forma aleatória. No Modelo 10 apenas a variável Idade mostrou-se significativa ao nível de 5\%, mostrando também que o tempo de mercado também influencia na divulgação de informações socioambientais pelas empresas.

Com relação ao Modelo 11, observou-se uma relação positiva da variável Comitê com o disclosure socioambiental (NDSA), apresentando-se significante ao nível de 1\%, corroborando com o preceituado na literatura (ULLMAN, 1985; ZAHRA; PEARCE, 1989; ADAMS, 2002; MICHELON; PARBONETTI, 2012). Outra variável que apresentou uma relação positiva com a divulgação de informações socioambientais foi a variável Influência da Comunidade (InfCom), sendo estatisticamente significante ao nível de 5\%. Segundo Hillman, Cannella Jr e Paetzold (2000) e Michelon e Parbonetti (2012), a presença de membros da comunidade em órgãos ligados ao conselho de administração das entidades busca legitimar as ações destas para com a sociedade, levando-as a impulsionar medidas que demonstrem para a população sua preocupação com as questões socioambientais.

Por outro lado, a variável que capta a relação entre a adoção aos níveis diferenciados de governança corporativa (Novo Mercado - NM) e o nível de disclosure da socioambiental (NDSA) apresenta uma relação negativa, mostrando-se significativa ao nível de $10 \%$. Este resultado diverge do preconizado pela literatura, uma vez que se espera que empresas que aderem a níveis diferenciados de governança corporativa busquem divulgar mais informações acerca das atividades organizacionais, buscando mitigar possíveis problemas de assimetria informacional entre os interessados nas companhias (SILVEIRA; BARROS, 2008).

Por fim, no Modelo 12, foram incluídas todas as variáveis de controle citadas na metodologia. Os resultados demonstram que apenas a variável Comitê, significante ao nível de $5 \%$, o tamanho das empresas, ao nível de $1 \%$ e o desempenho (ROE) ao nível de $1 \%$, apresenta um efeito positivo no nível de disclosure da sustentabilidade praticado pelas empresas pesquisadas, conforme previsto pela literatura. As demais variáveis para este modelo não apresentaram significância estatística.

Com relação às variáveis board interlocking (PartOut) e ocupação dos cargos de Diretor Executivo e Presidente do Conselho por pessoas diferentes (CEO), observou-se que estas variáveis parecem não influenciar ou se relacionar com o processo de divulgação de informações econômicas e socioambientais pelas organizações investigadas no período analisado, conforme demonstrado por outros estudos (HO, WONG, 2001; ULLMAN, 1985; ROBERTIS, 1992; CHEN; JAGGI, 2000; MICHELON; PARBONETTI, 2012).

Contudo, apesar de algumas variáveis relativas aos aspectos da governança corporativa não apresentarem relação com o disclosure da sustentabilidade praticado pelas empresas estudadas, observa-se que em firmas onde existem membros de famílias na administração das companhias, diretores independentes e membros da comunidade no conselho de administração e em entidades que mantêm um comitê ou órgão encarregado das políticas relativas à sustentabilidade empresarial parece que a divulgação dessas informações é incentivada. E, os resultados também sugerem que a adesão aos níveis diferenciados de governança corporativa parecem não influenciar no nível de divulgação das informações econômicas e socioambientais praticado pelas empresas.

\section{Considerações Finais}

O objetivo deste artigo foi verificar a relação entre o disclosure da sustentabilidade com algumas características da governança corporativa (dualidade do CEO, nível de governança corporativa, comitê de sustentabilidade ou de responsabilidade social, diretores independentes, Relação entre o Disclosure da Sustentabilidade com a Governança Corporativa: Um Estudo nas Empresas... 
administração familiar, influencia da comunidade e board interlocking) de empresas de capital aberto não financeiras listadas no IBrX-100 da BM\&FBOVESPA. Para isso, realizou-se uma pesquisa empírico-analítica onde se aplicou o método de regressão com dados em painel efeitos fixos e aleatórios para testar a relação entre a divulgação da sustentabilidade com as características da governança corporativa no período de 2009 a 2011.

Os resultados evidenciaram que no modelo de dados em painel com efeitos fixos apenas as variáveis idade (nos seis modelos), administração familiar (Modelos 1, 2 e 3), diretores independentes (Modelo 6), influencia da comunidade (Modelo 5 e 6) e Tamanho (Modelo 3 e 6) afetam positivamente o nível de disclosure da sustentabilidade corporativa, apresentando-se estatisticamente significante ao nível de $1 \%, 5 \%$ e $10 \%$. Estes resultados estão de acordo com o preconizado na literatura, e com estudos realizados anteriormente (TROTMAN; BRADLEY, 1981; HACKSTON; MILNE 1996; HANIFFA; COOKE, 2002; ADAMS, 2002; CHEN; CHEN; CHENG, 2008; MICHELON; PARBONETTI, 2012).

Nos modelos de dados em painel com efeitos aleatórios, os resultados também sugerem que as variáveis idade (Modelo 7, 8 e 10), comitê (Modelo 8, 9, 11 e 12), influência da comunidade (Modelo 11), Tamanho (Modelo 9 e 12) e desempenho (Modelo 12) apresentam uma relação positiva com o nível de divulgação de informações econômicas e socioambientais, mostrando-se estatisticamente significante ao nível de 1\%,5\% e 10\%, estando em consonância com a literatura (ULLMAN, 1985; ZAHRA; PEARCE, 1989; TROTMAN; BRADLEY, 1981; HACKSTON; MILNE 1996; HO; WONG, 2001; HANIFFA; COOKE, 2002; ADAMS, 2002; CHENG; COURTENAY, 2006; MICHELON; PARBONETTI, 2012).

Por outro lado, ressalta-se que a variável NM (referente à governança corporativa) apresentou uma relação negativa com o nível de disclosure da sustentabilidade corporativa (Modelo 11), sugerindo que as empresas que aderiram a esse nível diferenciando de governança corporativa apresentam um baixo nível de divulgação de informações se comparada às demais empresas investigadas. Este resultado diverge do esperado, uma vez que com a participação em níveis diferenciados de governança corporativa espera-se que as companhias busquem ser mais transparentes e divulguem mais informações acerca de suas atividades (BRAGA; SALLOTTI, 2008; IATRIDIS, 2013).

Além do ineditismo do trabalho, destaca-se como sua principal contribuição à literatura da área a evidenciação empírica de que algumas características da governança corporativa (como participação de membros familiares nos órgãos de administração, diretores independentes, influência de membros da comunidade e a presença de um órgão ou comitê responsável pelas políticas de responsabilidade socioambiental corporativa) parecem influenciar o disclosure da sustentabilidade corporativa praticado pelas empresas brasileiras de capital aberto. Por fim, a título de complementação para um melhor fundamento das análises, é necessário o desenvolvimento de mais pesquisas que busquem identificar o efeito do desempeno socioambiental no nível de disclosure da sustentabilidade corporativa, bem como na qualidade das informações divulgadas pelas companhias, uma vez que as empresas podem gerenciar as informações divulgadas ao seu público-alvo para mascarar um baixo desempenho socioambiental e legitimar suas atividades perante a sociedade.

\section{Referências}

ADAMS, C. A. Internal organisational factors influencing corporate social and ethical reporting: beyond current theorizing. Accounting, Auditing and Accountability Journal, v. 15, n. 2, p. 223-250, 2002. 
ADAMS, C. A.; MCNICHOLAS, P. Making a difference: sustainability reporting, accountability and organisational change. Accounting, Auditing and Accountability Journal, 20 (3), p. 382-402, 2007.

AGUILERA, R. et al. Corporate governance and social responsibility: A comparative analysis of the UK and the US. Corporate Governance: An International Review, v. 14, n. 3, p.147$158,2006$.

ALLEN, M. P. The structure of interorganizational elite cooptation: interlocking corporate directorates. American Sociological Review, vol. 39, n. 3, p. 393-406, Jun., 1974.

ASHCROFTH, P. A. Extent of environmental disclosure of U.S. and Canadian firms by annual report location. Advances in Accounting, incorporating Advances in International Accounting, v. 28, n. 2, p. 289-292, 2012.

BALLOU, B.; HEITGER, D. L.; LANDES, C. E. The future of corporate sustainability reporting: a rapidly growing assurance opportunity. Journal of Accountancy, p. 1-9, 2006.

BM\&FBOVESPA - Bolsa de Valores, Mercadorias e Futuros do Estado de São Paulo. Índice Brasil - IBRX. Disponível em: 〈http://www.bmfbovespa.com.br/indice>. Acesso em: 25 de nov. 2012.

BRAGA, J. P.; SALOTTI, B. M. Relação entre o nível de disclosure ambiental e características corporativas de empresas no Brasil. Congresso USP - Contabilidade e Controladoria, Anais..., 2008.

CHEN, S. et al. Are family firms more tax agressive than non-family firms? Jounal of Financial Economics, v. 95, n. 2, p. 41-61, 2010.

CHEN, S.; CHEN, X.; CHENG, Q. Do family provide more or less voluntary disclosure? Journal of Accounting Research, v. 46, n. 3, p. 499-536, 2008.

CHEN, E. C. M.; JAGGI, B. Association between independent non-executive directors, family control and financial disclosures in Hong Kong. Journal of Accounting and Public Policy, 19(4-5), p. 285-310, 2000.

CHENG, E. C. M.; COURTENAY, S. M. Board composition, regulatory regime and voluntary disclosure. The International Journal of Accounting, 41(3), p. 262-289, 2006.

COOKE, T. E. Disclosure in the corporate reports of Swedish companies. Accounting and Business Research, 19(74), 113-124, 1989.

DARMADI, S.; SODIKIN, A. Information disclosure by family-controlled firms. Asian Review of Accounting, v. 21, n. 3, p. 223-240, 2013.

DAVIS, G. F. The significance of board interlocks for corporate governance. Corporate Governance, vol. 4, n. 3, p. 154-59, Jul., 1996.

DEEGAN, C. The legitimising effect of social and enviromental disclosures - a theoretical foundation. Accounting, Auditing \& Accountability Journal, v. 15, n. 3, p. 282-311, 2002. 
DOOLEY, P. C. The interlocking directorate. The American Economic Review, vol. 59, n. 3, p. 314-323, Jun., 1969.

ENG, L. L.; MAK, Y. T. Corporate governance and voluntary disclosure. Journal of Accounting and Public Policy, v. 22, n. 4, p. 325-345, 2003.

FREEMAN, R. E. 1984. Strategic Management: a Stakeholder Appouch. Pitman: Marshall, 1984.

GAMERSCHLAG, R.; MÖLLER, K.; VERBEETEN, F. Determinants of voluntary CSR disclosure: empirical evidence from Germany. Review of Managerial Science, v. 5, n. 2-3, p.233-262, 2011.

GRAY, R. et al. Social and environmental disclosure and corporate characteristics: a research note and extension. Journal of Business Finance and Accounting, 28 (3), p. 327-356, 2001.

GRAY, R.; KOUHY, R.; LAVERS, S. Corporate social and environmental reporting: a review of the literature and a longitudinal study of UK disclosure. Accounting, Auditing and Accountability Journal, 8 (2), p. 47-77, 1995.

GUL, F. A.; LEUNG, S. Board leadership, outside directors' expertise and voluntary corporate disclosures. Journal of Accounting and Public Policy, 23(5), p. 351-379, 2004.

HACKSTON, D.; MILNE, M. Some determinants of social and environmental disclosures in New Zealand. Accounting, Auditing and Accountability Journal, 9 (1), p. 77-108, 1996.

HANIFFA, R. M.; COOKE, T. E. Culture, corporate governance and disclosure in Malaysian corporations. ABACUS, Vol. 38, n. 3, 2002.

HANIFFA, R. M.; COOKE, T. E. The impact of culture and governance on corporate social reporting. Journal of Accounting and Public Policy, v. 24, n. 5, p. 391-430, 2005.

HILLMAN, A. J.; CANNELLA, J.; PAETZOLD, A. A. The resource dependence role of corporate directors: strategic adaptation of board composition in response to environmental change. Journal of Management Studies, v. 37, n. 2, p. 235-255, 2000.

HO, C. Corporate governance and corporate competitiveness: an international analysis. Corporate Governance: An International Review, v. 13, n. 2, p. 211-253, 2005.

HO, S. M.; WONG, K. S. A study of the relationship between corporate governance structures and the extent of voluntary disclosure. Journal of Accounting, Auditing and Taxation, v. 10, n. 1, p. 139-156, 2001.

IATRIDIS, G. E. Environmental disclosure quality: Evidence on environmental performance, corporate governance and value relevance. Emerging Markets Review, v. 14, n. 1, p. 55-75, 2013.

IONEL-ALIN, I.; EMIL, P. I.; MARIA, I. N. Environmental reporting and good practice of corporate governance: petroleum industry case study. Procedia Economics and Finance, v. 3, n. 1, p. 961-976, 2012. 
JO, H.; HARJOTO, M. A. The causal effect of corporate governnce on corporate social responsibility. Journal of Business Ethics, v. 106, n. 1, p. 53-72, 2012.

KELLY, G. J. Australian social responsibility disclosure: some insights into contemporary measurement. Accounting and Finance, v. 21, n. 2, p. 97-104, 1981.

KOLK, A. A decade of sustainability reporting: devolopments and significance. International Journal and Sustainable Development, v. 3, n. 1, p. 51-64, 2004.

KOLK, A. Sustainability reporting. Vba Journal, n. 3, p. 34-42, 2005.

LEAL. M. J.; CAMURI, W. C. A governança corporativa e os modelos mundialmente praticados. Revista de Ciências Gerenciais, v. 12, n. 15, p. 59-74, 2008.

MACHADO, M. R. As informações sociais e ambientais evidenciadas nos relatórios anuais das empresas: a percepção dos usuários. 2010. Tese (Doutorado em Controladoria e Contabilidade: Contabilidade) - Faculdade de Economia, Administração e Contabilidade, Universidade de São Paulo, São Paulo, 2010.

MARTINS, G. A.; THEÓPHILO, C. R. Metodologia da investigação cientifica para Ciências Sociais Aplicadas. 2 ed. São Paulo: Atlas, 2009.

MICHELON, G.; PARBONETTI, A. The effect of corporate governance on sustainability disclosure. Journal of Management Governance, v. 16, n. 3, p. 477-509, 2012.

MITCHELL, R. K.; AGLE, B. R.; WOOD, D. J. Toward a theory of stakeholder identification and salience: defining the principle of who what really counts. Academy of Management Review, v. 22, n. 4, p. 853-886, 1997.

MIZRUCHI, M. S. What do interlocks do? An analysis, critique, and assessment of research on interlocking directorates. Annual Review of Sociology, vol. 22, p. 271-298, 1996.

PAULO, I. I. S. L. M.; CAVALCANTE, P. R. N. Estudo sobre o conservadorismo contábil nas companhias abertas familiares não-familiares no mercado brasileiro. In: $12^{\circ}$ CONGRESSO USP DE CONTROLADORIA E CONTABILIDADE, Anais..., 2012. Disponível em: $<$ http://www.congressousp.fipecafi.org/artigos 122012/592.pdf $>$. Acesso em: 25/11/2012.

REVERTE, C. Determinants of corporate social responsability disclore ratings by Spanish Listed firms. Journal of Business Ethics, v. 88, n. 2, p. 351-366, 2009.

ROBERTS, R. Determinants of corporate social responsibility disclosure: an application of stakeholder theory. Accounting, Auditing and Accountability Journal, v. 17, n. 6, p. 595$612,1992$.

ROVER, S.; MURCIA, F. D. Influência do disclosure voluntário econômico e socioambiental no custo de capital próprio das empresas brasileiras. In: IV Congresso Anpcont, 2010, Natal. IV Congresso Anpcont, 2010.

SALOTTI, B. M.; YAMAMOTO, M. M. Ensaio sobre a teoria da divulgação. Brazilian Business Review, v. 2, n. 1, p. 53-70, 2005. 
SILVEIRA, A. D. M.; BARROS, L. A. B. C. Determinantes da qualidade da governança corporativa das companhias abertas brasileiras. Revista Eletrônica de Administração, v. 14, n. 3, p. 1-29, 2008.

TROTMAN, K.; BRADLEY, G. W. Associations between social responsibility disclosure and characteristics of companies. Accounting, Organisations and Society, v. 6, n. 4, p. 355-362, 1981.

ULLMAN, A. Data in search of theory: a critical examination of the relationship among social performance, social disclosure, and economic performance. Academy of Management

Review, v. 10, n. 3, p. 540-577, 1985.

VERRECHIA, R. Essays on disclosure. Journal of Accounting and Economics, v. 22, p. 97 $180,2001$.

WEBER, J.; MARLEY, K. A. In search of stakeholder salience: exploring corporate social and sustainability reports. Business \& Society, v. 51, n. 4, p. 626-649, 2012.

WILLIAMS, S. M. Voluntary environmental and social accounting disclosure practices in the Asia-Pacific region: an international empirical test of political economy theory. The International Journal of Accounting, v. 34, n. 2, p. 209-238, 1999.

WOOLDRIDGE, J. M. Econometric analysis of cross section and panel data. MIT Press. 2010.

ZAHRA, S. A.; PEARCE, J. A. I. I. Boards of directors and corporate financial performance: A review and integrate model. Journal of Management, v. 15, n. 2, p. 291-334, 1989. 